\title{
RELACIONES PÚBLICAS, RESPONSABILIDAD SOCIAL CORPORATIVA E IMAGEN PÚBLICA EN LA ACTUAL CRISIS
}

\section{PUBLIC RELATIONS, CORPORATE SOCIAL RESPONSIBILITY AND PUBLIC IMAGE IN THE CURRENT CRISIS}

Luis Felipe Solano Santos: Facultad de Ciencias de la Información de la Universidad Complutense de Madrid. (España)

felipe.solano@ccinf.ucm.es

\section{CURRÍCULUM VITAE}

Doctor en Ciencias de la Información. Licenciado en Periodismo por la Facultad de Ciencias de la Información de la Universidad Complutense de Madrid (España). Es miembro de un Grupo de Investigación Validado Complutense y director de varios proyectos de investigación. Ponente en varios Congresos nacionales e internacionales. Ha publicado tres libros y numerosos artículos en libros y revistas científicas.

\section{RESUMEN}

¿Qué relación existe en el ámbito de las Relaciones Públicas, entre la denominada imagen pública de una institución y el grado de asunción de responsabilidad que expresa con su conducta dicha institución? Las Relaciones Públicas hace referencia a la rama de la comunicación que se encarga de crear, modificar y/o mantener la imagen positiva ya sea de una empresa, organización, ente público o privado, o persona; y fortalecer los vínculos con todos sus públicos, utilizando diferentes 
estrategias, técnicas e instrumentos. Su misión es generar un vínculo entre la organización, la comunicación y los públicos relacionados. Es una ciencia en desarrollo que emplea métodos de otras áreas como la publicidad, el márketing o el periodismo, entre otras. Es una disciplina que tiene por objeto la realización de un valor, la solidaridad social. Se tratará de diferenciar entre esta idea y la de responsabilidad social.

\title{
PALABRAS CLAVE
}

Relaciones Públicas - Responsabilidad Social - Solidaridad - Imagen Pública

\begin{abstract}
What is the relationship in the field of Public Relations, among the so-called public image of an institution and the degree of assumption of responsibility expressed by their conduct that institution? Public Relations refers to the branch of communication that is responsible for creating, modifying and / or maintain the positive image of either a company, organization, public or private entity or person, and strengthen ties with all its stakeholders, using different strategies, techniques and tools. Its mission is to create a link between the organization, communication and related public. It is a developing science that uses methods from other areas such as advertising, marketing or journalism, among others. It is a discipline that aims at the realization of a security, social solidarity. This will be the difference between this idea and social responsibility.
\end{abstract}

\section{KEY WORDS}

Public Relations - Social Responsibility - Solidarity - Public Image 


\section{ÍNDICE}

1. Introducción.

2. Relaciones Públicas.

3. Responsabilidad Social Corporativa.

4. Imagen Pública

5. Conclusiones.

6. Bibliografía

\section{TEXTO}

\section{Introducción}

¿Qué relación existe en el ámbito de las Relaciones Públicas, entre la denominada imagen pública de una institución y el grado de asunción de responsabilidad que expresa con su conducta dicha institución? ¿Cómo ha repercutido el incumplimiento de la misma en la actual coyuntura económica que atraviesa la actual civilización denominada desde hace tiempo como "sociedad de la imagen"? ¿Se ha hecho lo suficiente a nivel internacional en lo que responsabilidad social corporativa se refiere o sus actuaciones no han sido más que brindis al sol? Para contestar a estas preguntas es necesaria la construcción de un marco teórico y este no puede ser otro que el concepto de Relaciones Públicas tanto como actividad pragmática como conjunto de saberes e ideología.

Las Relaciones Públicas son una disciplina valorativa y finalista, en cuanto tienen por objeto la realización de un valor, la solidaridad social, a través de procesos de 
comunicación específicos. A lo largo de las próximas líneas pretendemos establecer que la solidaridad social, objetivo último de las Relaciones Públicas, está en función del grado de asunción de responsabilidad de esta naturaleza que expresa una empresa, institución u organización con su conducta, que se resuelve en lo que se denomina imagen pública o reputación. En consecuencia, existe una relación causal entre tres factores: la concepción de las Relaciones Públicas de que partimos, la naturaleza y alcance de la llamada responsabilidad social y que se entiende por imagen pública o reputación corporativa. En definitiva, que la imagen pública es consecuencia directa del cumplimiento o asunción de su responsabilidad social o, mejor dicho, del grado de convicción social acerca de su cumplimiento. Ello viene a coincidir con el fundamento de las propias Relaciones Públicas, es decir, el grado de aceptación social de una persona, empresa o institución está en función de su comportamiento de esta naturaleza, que no es otro que el correspondiente al comportamiento esperado.

En otras palabras, el presente artículo pretende establecer la relación causal entre la idea de solidaridad y responsabilidad social, de un parte; de otra, la relación asimismo causal entre asunción de responsabilidad social e imagen pública. O de otro modo, la solidaridad social es una consecuencia directa de la asunción de la responsabilidad; la imagen pública es, a su vez, consecuencia directa del grado de solidaridad manifestado. Por lo tanto, extrapolando dicha idea y aplicándola a la actual situación se puede deducir que la negativa imagen que proyectan ahora la mayoría de las organizaciones tanto públicas como privadas, es decir, las distintas administraciones generales del Estado; entidades bancarias y la mayor parte de empresas de toda índole, responde a una inadecuada y desacertada gestión, entre otros motivos, por la falta absoluta de responsabilidad social. 


\section{Relaciones Públicas}

Las Relaciones Públicas constituyen un saber nacido de la práctica y para la práctica. De este modo podemos establecer los principios fundamentales que pasan, por supuesto, por que las Relaciones Públicas son una ciencia cultural, valorativa y finalista. Es decir, pretenden, como hemos citado anteriormente, la realización de un valor: la solidaridad. Esta pretensión se realiza generalmente a través de procesos de comunicación grupales e intergrupales generadores de una reputación social óptima que traduce en cada supuesto concreto los valores de la norma de cultura.

Pero, el concepto de Relaciones Públicas no es pacífico entre los autores y tampoco entres los profesionales que se dedican a ello. De hecho, existen importantes diferencias que los separan. Por el contrario, coinciden en afirmar que las Relaciones Públicas son comunicación y comunicación finalista.

Ahora bien, las Relaciones Públicas tienen por objeto incrementar la cohesión social de los individuos y los grupos, a través de la realización de un valor, la solidaridad, mediante procesos de comunicación específicos y ahí es donde reside su singularidad y su justificación científica.

\section{Responsabilidad social corporativa}

Si la responsabilidad social es la capacidad en toda persona de conocer y aceptar las consecuencias de un acto suyo, inteligente y libre, así como la relación de causalidad que une al autor con el acto que realiza, vinculando en aquel las relaciones nacidas de los efectos de éste; que responsabilidad equivale a obligación o conjunto de obligaciones derivadas de la libre asunción de un estado o condición; y que hablar de obligación nos remite directamente al problema de la costumbre, norma creada e 
impuesta por el uso social como afirma el profesor Federico de Castro; podría decirse que responsabilidad social es el conjunto de obligaciones inherentes a la libre asunción de un estado o condición, aún no tipificadas por el ordenamiento jurídico positivo o reconocidas sólo parcialmente, pero cuya fuerza vinculante y previa tipificación proceden de la íntima convicción social de que se incumplimiento constituye una infracción de la norma de cultura. Y qué es la norma de cultura, por de pronto, una intuición perteneciente a una cultura determinada, que atribuye unos valores a ciertos hechos. Es una intuición que nos permite saber lo que es bueno y lo que no es bueno. Sin duda, es como el sedimento de una cultura y en cierto sentido irracional.

A nivel internacional se han realizado esfuerzos para fomentar la responsabilidad social de las empresas. Aun reconociendo su valor, las iniciativas propuestas no satisfacen plenamente, ya que se trata, en definitiva, de declaraciones voluntaristas, aptas para tranquilizar las conciencias, pero muy alejadas de lo que se desea y desde luego, se pretende con mayor o menor fortuna. Se trata del Libro Verde, el Pacto Mundial, el Protocolo de Kioto y, más actualmente, las numerosas citas, denominadas cumbres, a las que han acudido los máximos responsables de las naciones del mundo con objeto de abordar la crisis. A priori, puede parecer que tal vez sea lo único que cabe hacer y en este sentido está muy en la línea de lo que son y representan las Naciones Unidas, organización que se caracteriza por sus buenas intenciones pero también por su tibieza; de ahí que, en la hora presente, se halle en crisis, una crisis estructural, pero cuyos fundamentos hay que buscarlos más que en el presente en los errores que se han cometido en el pasado. A fin de cuentas, la ONU es heredera directa de la extinta Sociedad de Naciones y arrastra, más o menos conscientemente, errores análogos a los de su causahabiente; si a ello se une el haber sido inicialmente una organización creada por y para los vencedores de la Guerra Mundial, no debe extrañarnos la situación en que se haya. 
El Pacto Mundial, el Libro Verde, el Protocolo de Kioto y dichas cumbres son actitudes sociales que en los albores del siglo XXI se mantienen respecto de la responsabilidad social de las instituciones y que, de un modo u otro, se fundamentan en la "norma de cultura". Es hora de adoptar medidas mucho más rigurosas y fundamentadas y que, por supuesto, se asuman de forma absoluta.

En 1993, el llamamiento del presidente Jack Delors a las empresas europeas para que participaran en la lucha contra la exclusión social dio lugar a la creación de redes europeas de empresas. La Unión Europea estaba interesada en la responsabilidad social de las empresas en la medida que podían contribuir positivamente al objetivo estratégico de crecer económicamente de manera sostenible con más y mejores empleos y con mayor cohesión social. Así se estableció en marzo de 2000 en el Consejo de Lisboa, del que nació el Libro Verde, una herramienta que pretende la creación de un marco europeo favorable para la responsabilidad social de las empresas, es decir, para que contribuyan al logro de una sociedad mejor y un medio ambiente más limpio. Es cierto que cada vez eran más las empresas que fomentan sus estrategias de responsabilidad social en respuesta a presiones sociales, económicas y medioambientales, ya que al asumir dichos compromisos invertían en su futuro y esperaban incrementar su rentabilidad al adoptarlos voluntariamente.

En cuanto al Pacto Mundial, este fue anunciado por el Secretario General de las Naciones Unidas, Kofi Annan, en el Foro Económico Mundial, en Davos (Suiza), en enero de 1999, y puesto en marcha desde la sede de las Naciones Unidas en julio de 2000. El Pacto Mundial es un llamamiento a las empresas con el fin de que adopten una serie de principios universales en el ámbito de los derechos humanos, normas laborales y medio ambiente. Agrupa a empresas, asociaciones internacionales de trabajadores y organizaciones no gubernamentales con organismos de las Naciones Unidas y otras instancias para fomentar la colaboración y crear un mercado mundial 
más equitativo con cabida para todos. Su principal objetivo es que la adopción de valores y principios compartidos den un rostro humano al mercado mundial, ya que se crea para ayudar a las organizaciones a definir sus estrategias y modalidades de acción, de forma que todas las personas y no sólo unos pocos afortunados puedan beneficiarse de las ventajas de la globalización. Se propuso que a través del un liderazgo empresarial comprometido y creativo podrían cumplirse esos objetivos. Los principios universales eran los siguientes:

1. Las empresas deben apoyar y respetar la protección de los derechos humanos proclamados a nivel internacional.

2. Deben evitar verse involucradas en abusos de los derechos humanos.

3. Las empresas deben respetar la libertad de asociación y el reconocimiento efectivo del derecho a la negociación colectiva.

4. Deben eliminar todas las formas de trabajo forzoso y obligatorio.

5. Deben también colaborar en la abolición efectiva del trabajo infantil.

6. Así como en la erradicación de la discriminación respecto del empleo y la ocupación.

7. Las empresas deben apoyar la aplicación de un criterio de precaución respecto de los problemas ambientales.

8. Deben adoptar iniciativas para promover una mayor responsabilidad ambiental. 
9. Deben alentar el desarrollo y la difusión de tecnologías inocuas para el medio ambiente.

Años más tarde se incluye un nuevo principio que dice:

10. Deben luchar contra todo tipo y forma de corrupción.

Ahora bien, la coyuntura económica hace necesaria e imprescindible la inclusión de algún principio más en relación al cumplimiento de la responsabilidad social por parte de las empresas tanto públicas como privadas con objeto de evitar que en un futuro vuelva producirse una situación como la que ahora vivimos. Es decir, principios referentes a la adopción de medidas encaminadas a exigir ese cumplimiento como podrían ser la transparencia absoluta de las actividades económicas, un mayor control por parte de los gobiernos y un compromiso económico para con la sociedad.

Por otra parte, el denominado Protocolo de Kioto es un acuerdo internacional asumido en 1997 en el ámbito de Naciones Unidas que trata de frenar el cambio climático. Uno de sus objetivos es contener las emisiones de los gases que aceleran el calentamiento global, y hasta la fecha ha sido ratificado por 163 países. El acuerdo impone para 39 países que se consideran desarrollados la contención o reducción de sus emisiones de gases de efecto invernadero.

Indudablemente se trata de una iniciativa que nace de la premisa de que el planeta sufre como han denominado un cambio climático, algo que es cuestionable. Pero dejando a un lado dicho aspecto, aunque refleja la intención del cumplimiento de responsabilidad en un aspecto tan importante como el medio ambiente, el Protocolo 
de Kioto no deja de ser eso, un conjunto de buenas intenciones, cuyo cumplimiento, no es que se deje al arbitrio de las naciones comprometidas que se deja, sino que en muchos supuestos dudoso y de escasa eficacia.

Por otra parte, durante los últimos meses las principales potencias mundiales y otras no tan desarrolladas han adquirido el compromiso de abordar la actual crisis con la intención de superar la coyuntura lo mejor y antes posible. Las denominadas "cumbres" no tienen más propósito que abordar las medidas necesarias que se han de adoptar para ello, que, por supuesto, pasan por la denominada responsabilidad social.

\section{Imagen corporativa}

Evidentemente al hablar de imagen corporativa se alude a la imagen de la corporación, término que renaces siglos después con los aires nuevos de un anglicismo, "corporate", que apenas conserva relación alguna con sus raíces originales, hundidas en la Europa medieval, tal y como afirma Joan Costa en su obra "Comunicación corporativa y revolución de los servicios".

Corporación es sinónimo de organización y se refiere o indica una empresa o también una organización de empresas. Sin embargo, sería mucho más correcto que la corporación aludiese a aquellas organizaciones o entidades sociales que por su volumen y capacidad están en condiciones de liderar el progreso social en todos los órdenes.

Por otra parte, ¿qué es y en qué consiste eso que se denomina imagen pública? Pues bien, la imagen es la representación intelectual de un objeto; y más concretamente, la representación mental en el imaginario colectivo de un conjunto de atributos y 
valores que funcionan como un estereotipo y determinan la conducta y opiniones de esa colectividad.

La imagen es producto de la relación de dos factores o elementos, unos subjetivos, y otros objetivos. Entre los subjetivos se encuentran los intereses, las necesidades y los prejuicios, es decir, los que según la psicología social integran la triada psicológica. Y entre los objetivos destaca el denominado carácter nacional, es decir, el conjunto de características y estilos de vida distintivos de los ciudadanos de una nación. Se trata, cómo no, de la respuesta del hombre al desafío del medio.

Pero hay tantas imágenes como públicos, es decir, aun siendo una la imagen de una organización o entidad, ésta es poliédrica, ya que cada público contempla dicho ente desde una perspectiva distinta e influyen en él intereses y necesidades distintas. Según el concepto poliédrico de la imagen:

1. La imagen es una, siquiera su naturaleza es poliédrica.

2. El carácter poliédrico de la imagen está en función de la diversa perspectiva de los públicos de la empresa.

3. El carácter poliédrico de la imagen significa que de la diversidad de propiedades que la configuran, cada público es sensible en mayor o menor grado a unas que a otras.

4. La imagen es el resultado de comparar la realidad con la idealidad.

5. La idealidad está constituida por la imagen arquetípica. 
6. La imagen arquetípica es la cristalización de numerosos factores históricos entre los que destaca el carácter nacional.

7. La posibilidad de modificar la imagen arquetípica es prácticamente nula, ya que es manifestación de actitudes colectivas básicas, primarias o fundamentales.

\section{Conclusiones}

De acuerdo con lo expuesto, se establece que toda persona, institución u organización que acomode su conducta a los requerimientos sociales, es decir, al comportamiento esperado, de acuerdo con la norma de cultura de dicha sociedad, disfrutará de una imagen pública o reputación buena, en el sentido de ser reconocida como valiosa. La imagen pública es la expresión manifiesta de la aceptación social por cuanto traduce el caso concreto la convicción o sentir de la colectividad. Por ello, la actividad de las Relaciones Públicas, endereza a la creación y mantenimiento de la cohesión social, a través de procesos de comunicación específicos que desarrollan el valor solidaridad se manifiesta en lo que ha dado en llamarse imagen corporativa, imagen pública o reputación pública y que ésta es la consecuencia de un comportamiento adecuado a la norma de cultura y que en tanto dicha conducta traduzca los requerimientos sociales básicos, la organización será aceptada como un ciudadano corporativo, que es, en última instancia, lo que expresa la imagen corporativa, imagen pública o reputación pública.

Es decir, extrapolando dicha conclusión puede establecerse que la actual imagen negativa que proyectan las distintas entidades sociales de toda índole es producto del incumplimiento de la responsabilidad social en el ámbito de las Relaciones Públicas. No sólo no se han asumido los requerimientos sociales, sino que además la propia función o labor de cada una de ellas que, por supuesto, engendra responsabilidad 
social, ha sido un fracaso y prueba de ello es el derrumbe financiero, la ineficaz maniobra de los gobiernos hasta ahora para frenar la recesión mundial y la quiebra de multinacionales, empresas, pymes, así como la desorbitada y espeluznante cifra de desempleados en naciones como los Estados Unidos, España y otros países que lideran el desarrollo social mundial.

\section{Bibliografía}

CAPRIOTTI, Paul (1999): "Planificación estratégica de la Imagen Corporativa", Barcelona, Ariel.

COSTA, Joan (1993): “Imagen pública, una ingeniería social”, Fundesco, Madrid.

COSTA, Joan (1995): "Comunicación corporativa y revolución de los servicios", Madrid, Ciencias Sociales.

COSTA, Joan (2001): "Imagen Corporativa en el siglo XXI", La Crujía Ediciones, Buenos Aires.

CUESTA, Marta de la y GALINDO, Angel (Coords.) (2005): “Inversiones socialmente responsables".

CUESTA, Marta de la y RODRÍGUEZ DUPLÁ, Leonardo (coords.) (2004): "Responsabilidad Social Corporativa".

CUESTA, Marta de la, VALOR MARTÍNEZ, Mamen y SANMARTÍN SERRANO, Sergio (2002): "Inversiones éticas en empresas socialmente responsables”. 
FINN, D. (1964): La Empresa y las Relaciones Públicas", Barcelona.

FLORES BAO, F. (1981): “Relaciones Públicas. Ciencia de la integración humana”, Lima.

FLORES BAO, F. (1969): Teoría y práctica de las Relaciones Públicas”, Lima.

G. PERDIGUERO, Tomás (2003): “La responsabilidad social de las empresas en un mundo global".

LOUGOVOY, C. y LINON, M. (1972): “Relaciones Públicas”, Barcelona.

MONTEVIDEO.RAY, V. (1971): “Cómo iniciarse en Relaciones Públicas”, Buenos Aires.

MOORE, H. F. y CANFIELD, B. R. (!980): “Relaciones Públicas. Principios, Casos y Problemas", México.

PÉREZ SENAC, R. (1975): “Las Relaciones Públicas y el Agro”, Montevideo.

PÉREZ SENAC, R. (1980): “Las Relaciones Públicas en la década de los 80”,

SARUBA, J. (1972): “Las Relaciones Públicas piden la palabra”, Buenos Aires.

SEIL, M. D. (1982): “Relaciones Públicas y Publicidad”, Quito.

SLEE SMITH, P. (1970): "Relaciones Públicas de la Empresa”, Bilbao. 
SOLANO FLETA, L. (1988): “Tratado de Relaciones Públicas”, Madrid.

SOLANO FLETA, L. (1995): “Fundamentos de las Relaciones Públicas”, Madrid.

UGEUX, W. (1976): “Las Relaciones Públicas. Una nueva función social”, Barcelona.

VILLAFAÑE GALLEGO, Justo (1993): "Imagen positiva. Gestión estratégica de la imagen de las empresas", Madrid, Ediciones Pirámide. 